\title{
Acute Centro-facial Pigmentation - A sign of Viral Exanthem ?: Case Reports
}

\section{Shilpakar $\mathbf{R}^{1}$, Velugotla $\mathbf{K}^{2}$, Sachdev $\mathbf{M}^{3}$}

${ }^{1,2}$ Consultant Dermatologist, MS Skin Centre, Bangalore, India, ${ }^{3}$ Senior consultant Dermatologist, Manipal Hospital, Bangalore, India and Medical Director, MS Skin Centre, Bangalore, India.

\author{
Address for correspondence \\ Dr. Rachana Shilpakar \\ MS Skin Centre \\ $36 / 1,7$ th cross, 1 st main \\ Cambridge layout, Bangalore 560008, India \\ Phone number: +919900219182 \\ E-mail: rachanashilpakar@gmail.com
}

Conflict of Interest: No

\begin{abstract}
We report two cases of abrupt onset centro-facial pigmentation associated with acute viral fever and arthralgia. Review of literature yielded reports of similar pigmentation along with other dermatological manifestations like maculopapular rash, vesiculobullous lesions etc. In our cases centrofacial pigmentation confined to nose was the only presenting symptom and required treatment from patient's perspective.

Centro-facial melanosis may be considered as a sign of acute viral fever which could require specific treatment.

The aim of our report is to widen the vision of clinicians in considering abrupt onset of centro-facial melanosis as a presenting symptom in an acute sero-negative viral fever with arthralgia.
\end{abstract}

Key words: acute centrofacial pigmentation, chikungunya fever, acute viral exanthema

\section{Introduction}

A arge variety of skin and mucous membrane lesions have been reported in association with acute viral illness. The most common cutaneous manifestation described in acute viral exanthema is generalised maculopapular eruption followed by aphthous ulcers and cutaneous pigmentation. We report two cases of acute centrofacial pigmentation as the only cutaneous manifestation in viral illness.

\section{Case 1}

A 54 years old female presented with pigmentation of nose since 2 days. The pigmentation was preceded by a high grade, continuous fever with malaise and joint pains of 4 days. The pigmentation was abrupt in onset, asymptomatic and without previous history of rash. There was no history of excessive sun exposure, no history of usage of local irritants such as vicks vaporub, zandu balm (which is a very common practice in India for rhinitis, sinusitis, and headache). No history of drug intake and alternative therapy. The patient is a non diabetic, non hypertensive and not on any oral medications and supplements.

On examination, the patient was febrile. Dermatological examination revealed blotchy, uniform dark brown macules over the bridge of nose extending over the sides (Fig 1). There were no similar pigmentary changes on any other part of the body apart from the nose. No evidence of erythematous maculopapular eruptions on other areas. Oral mucosa, conjunctiva, genitalia, palms and soles were normal.

A clinical diagnosis of acute febrile illness associated with centro- facial pigmentation was made. In view of the high prevalence of viral infections, particularly dengue and chikungunya fever in south India, patient was advised to undergo specific serological investigations. The patient was symptomatically treated with anti-pyretic, soft diet and rest. 
The patient was reviewed 3 days later with blood reports which showed mild leucopenia, neutropenia, mild lymphocytosis, basophilia and mild reduction in platelet counts. NS1 antigen for dengue and chikungunya specific IgM, IgE antibodies were negative. The patient was afebrile with severe arthralgia, unable to perform daily activities. No new pigmentation was observed at other areas apart from nose and no viral exanthem like lesions were present.

With the constellation of presenting symptoms and laboratory blood picture, the diagnosis of centro-facial melanosis with acute febrile illness of viral aetiology was made, although the specific serological tests were negative. The patient was extremely self conscious due to hyperpigmenation of nose and seeked remedy for the same. The patient was advised spot application of Kligman formula ( $2 \%$ hydroquinone, $0.05 \%$ tretinoin, $0.01 \%$ fluocinolone acetonide) cream at night and licorice-arbutin combination cream in the morning along with regular repeated application of broadspectrum sunscreen for 1 month.

The patient followed up after a month. The pigmentation over nose had improved but was still present (Fig 2). She complained of persistent joint pain. She was advised to continue licorice-arbutin cream along with sunscreen, analgesics for joint pains and to follow up after a month.

\section{Case 2}

A 61 years old non diabetic, non hypertensive male presented with pigmentation over the nose since 2 weeks. History revealed that the patient had fever, malaise and joint pains 3 weeks back for which he was treated symptomatically with analgesics and antipyretic. One week later patient noticed abrupt onset of asymptomatic pigmentation over the nose without previous history of rash. No history of drug intake, sun exposure, usage of local irritants prior to pigmentation.

Dermatological examination revealed blotchy dark brown macules on bridge of nose extending on to the sides and ala of nose (Fig 3). Oral mucosa, conjunctiva, genitalia, palms and soles were normal.

A provisional diagnosis of centro facial melanosis as a sequela to an acute viral illness was made. The patient was treated with Kligman formula at night and licorice- arbutin cream in the morning along with a broad-spectrum sunscreen for a month and is due for followup.

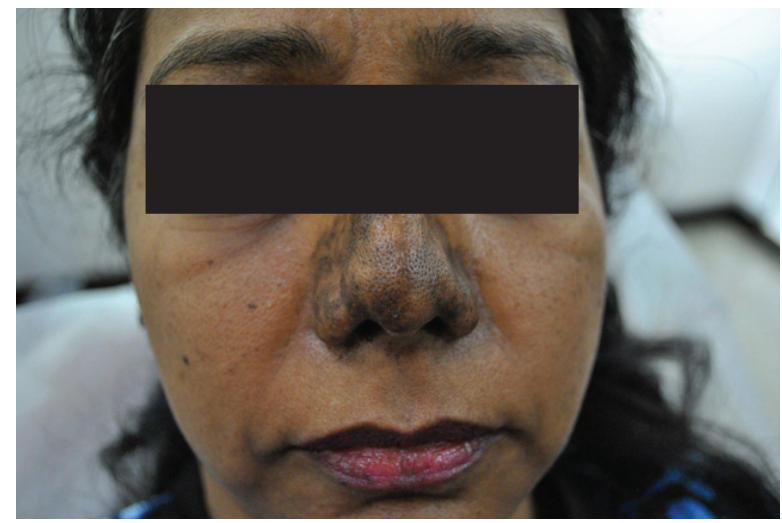

Fig 1: A 54 years old female with nose pigmentation of 2 days duration.

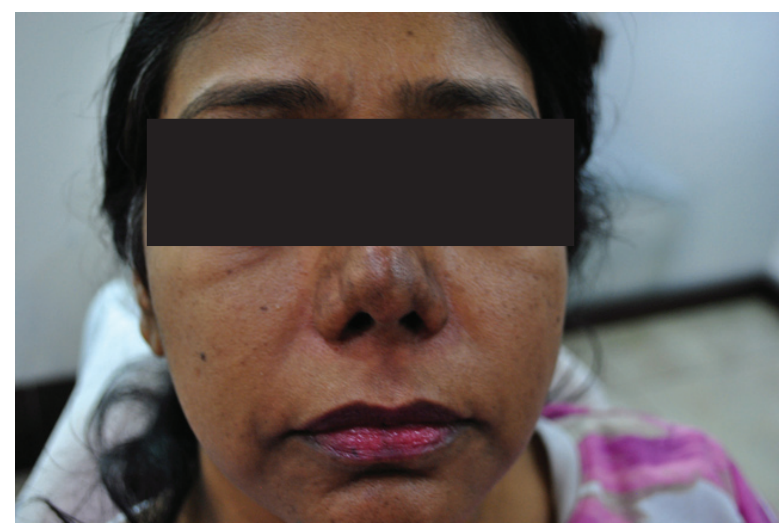

Fig 2: Improvement of nose pigmentation 2 months post treatment

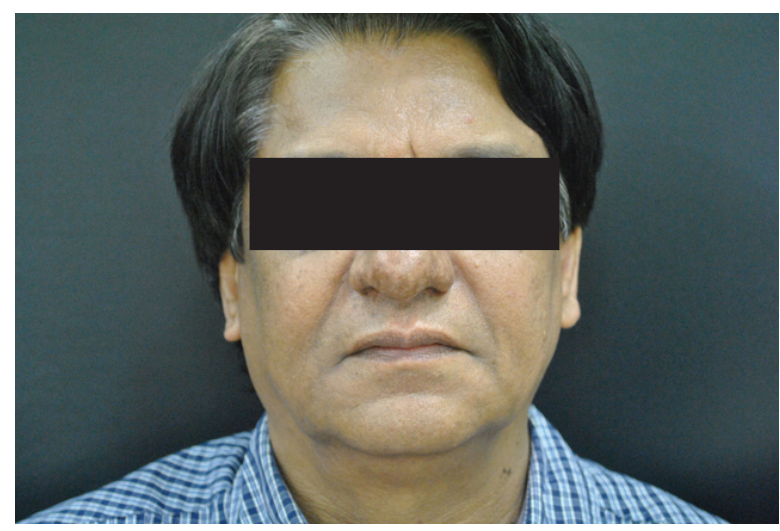

Fig 3: A 61 year old male with nose pigmentation of 2 weeks duration.

\section{Discussion}

A large variety of skin and mucous membrane lesions have been documented to occur in association with acute viral illness. A generalised maculopapular eruption is the most common cutaneous manifestation described in acute viral exanthem such as chikungunya ${ }^{1,2,3}$ and dengue followed by aphthous ulcers and cutaneous pigmentation. Other less common presentation includes vesicobullous lesions (particularly in children) ${ }^{4}$, xerosis and scaling, 
desquamation of palms, soles and face, excoriated papules, generalised erythema, transient nasal erythema, cutaneous necrotic ulcers, ecchymosis, generalized urticarial lesions and even exacerbation of pre existing dermatoses ${ }^{4}$.

Pigmentary changes have been one of the common presentations in viral illness ${ }^{1,2,3,4,5}$. Mechanism of pigmentation can be post inflammatory ${ }^{5}$. An increase in intraepidermal melanin dispersion/retention triggered by the virus has also been suggested ${ }^{6}$. An exposure to ultraviolet rays in case of pigmentation in exposed areas may be contributory ${ }^{3,6}$. With the stimulation of reticulo-endothelial system by chronic infections and consequent reduced adrenocortical activity, enhanced pigmentation of skin has been stated ${ }^{7}$.

Inamadar AC et $a l^{6}$ has reported asymptomatic brownish-black pigmentation, predominantly involving centrofacial area as the most common cutaneous feature observed amongst suspected cases of chikungunya in their observational study. Shivakumar $\mathrm{V}$ et $a l^{7}$ has reported an abrupt onset of unusual

\section{References}

1. Bandyopadhyay D, Ghosh S.K. Mucocutaneous manifestations of Chikungunya fever. Indian J Dermatol 2010; 55(1): 64-67. https://doi. org/10.4103/0019-5154.60356

2. Prashant S, Kumar AS, Mohammed BDD, Chowdhary TN, Madhu B. Cutaneous manifestations in patients suspected with chkungunya disease. Indian J Dermatol 2009; 54: 128-31. https://doi.org/10.4103/00195154.53186

3. Bhat RM, Rai Y, Ramesh A, Nandakishore B, Sukumar D, Martis J et al Mucocutaneous manifestations of chikungunya fever: A study from an epidemic in coastal Karnataka. Indian J Dermatol 2011; 56: 290-4. https://doi. org/10.4103/0019-5154.82483

4. Seetharam KA, Sridevi K, Vidyasagar P. Cutaneous manifestations of chikungunya fever. Indian Pediatr 2012; 49(1): 51-3. https:// doi.org/10.1007/s13312-012-0007-7 facial melanosis in viral fever without any preceding symptoms. Riyaz $\mathrm{N}$ et $a l^{5}$ observed a striking nose pigmentation in a large number of patients and hence suggested to consider this peculiar pigmentation as a marker for chikungunya fever and proposed a "chik sign." Kalane $S$ et $a l^{8}$ reported congenital chikungunya with centro-facial pigmentation. Bandyopadhya D et a ${ }^{1}$ has stated delayed cutaneous manifestation in a form of hyperpigmentation which may persist for months after remission of chikungunya. In our cases, abrupt onset centro-facial melanosis was the only cutaneous manifestation which presented and persisted for more than a month.

\section{Conclusion}

The aim of our case reports is to widen the vision of clinicians in considering abrupt onset of centro-facial melanosis as a presenting symptom in an acute seronegative viral fever with arthralgia - a viral exanthem.

Acknowledgements : Nil

5. Riyaz N, Riyaz A, Rahima, Abdul LEN, Anitha PM, Aravindan KP et al. Cutaneous manifestations of chikungunya during a recent epidemic in Calicut, North Kerala, South India. Indian J Dermatol Venereol Leprol 2010; 76: 671-6. https://doi.org/10.4103/0378-6323.72466

6. Inamdar AC, Palit A, Sampagavi NV, Raghunath $S$, Deshmukh NS. Cutaneous manifestations of chikungunya fever: Observations made during a recent outbreak in South India. Int J Dermatol 2008; 47: 154-9. https://doi.org/10.1111/j.13654632.2008.03478.x

7. Shivakumar V, Okade R, Rajkimar V, Rajashekar TS. Unusual facial melanosis in viral fever. Indian J Dermatol 2007; 52: 116-7. https://doi. org/10.4103/0019-5154.33295

8. Kalane S, Joshi R, Rajhans A. Congenital Chikungunya with Centro-facial Pigmentation and Persistent Thrombocytopenia: A Case Report. Int J Pediatr 2015; 3: 575-78. 